had got eight ounces of port wine surreptitiously, and drunk it the night before the commencement of the unfavourable symptoms.

CASE LXVII.-John M'Intyre, aged 63, a pensioner, was admitted on February 17 th, 1847 ; and on April 17 th, a stone, weighing 2 ounces, and measuring $2 \frac{3}{8}$ inches by $1 \frac{3}{8}$ inches by $I_{8}^{7}$ inches, was removed. He went on for a few days very well ; but after that time a troublesome cough came on, the result of chronic pulmonary disease, and he gradually became weaker, and died on the morning of May 14th. At the post mortem examination, the viscera of the belly and pelvis were found quite healthy. The right pleural cavity contained a large quantity of purulent effusion, and numerous vomicæ were found in both lungs.

CASE LXX. - Isaac Routledge, manufacturer, aged 73, came under treatment on May 22nd, 1847 , and was operated on June 5 th. Five calculi, weighing $1 \frac{1}{2}$ ounces, and the largest measuring $1 \frac{3}{8}$ inches by $\frac{3}{4}$ inch by $I \frac{1}{8}$ inches, were removed. He died exhausted on June 28 th from no very evident cause, the powers of life gradually failing under despondency. No post mortem examination was allowed.

CASE LXXI.--Alexander Davidson, aged 52, farmer, was admitted on October 9th, 1847 , and on the 30 th was operated on, when a stone, weighing $6 \frac{1}{2}$ drachms, and measuring $1 \frac{3}{4}$ inches by $\frac{3}{4}$ inch by $I_{2}^{1}$ inches, was removed. A pendulous polypous tumour was felt within the neck of the bladder, and on withdrawing the stone the excrescence came away in the angle of the blades. For some time after the operation the urine was bloody and mixed with coagula. In the evening the tube was removed, and, after being enveloped in lint soaked with tincture of matico, was reintroduced. On the morning of the 31 st, the urine was more clear and copious; the wine which he had been getting during the night was continued; in the evening the pulse was 100 , as it had been since the operation; the urine was less copious, and the belly somewhat tumid. He passed a restless night, became confused, his pulse rose in frequency and became more feeble, and he died at I I A.M. on November Ist. No post mortem examination was allowed.

CASE LXXIII. - John Topp, aged 63, crofter, was admitted on December 15th, 1847, and operated on December 25th, when two stones, weighing $3 \frac{1}{4}$ ounces, were removed. 'The larger measured $2 \frac{3}{8}$ inches by $I_{4}^{\frac{1}{4}}$ inches by $\mathrm{I} \frac{5}{8}$ inches. He went on well for twenty-four hours, but after that the urine became less and less in quantity, the pulse quick and weak, and the tongue dry, and he died on the 27 th at half-past seven in the evening. At the post mortem examination there was not the least trace of inflammatory action in the abdomen or pelvis. The right kidney had numerous cysts on its surface, and Bright's disease had made some progress throughout the gland; the left kidney was atrophied, with the pelvis remaining like a bladder.

CASE LXXVI.-Peter Pirie, aged 45, farmer, was admitted on March Ioth, I848, and was operated on April I 5 th. The stone weighed 3 drachms, and measured $1 \frac{1}{2}$ inches by $\frac{5}{5}$ inch by 1 inch. He went on very well, and the wound had entirely closed; when he was attacked by erysipelas of the head and neck, then prevalent in the hospital, and died on April 29th.

CASE LXXVIII. - William Ross, aged 67, weaver, was admitted on August 22nd, 1848, and operated on September 2nd. Two stones, weighing 2 ounces 6 drachms, were removed, the larger measuring I inches by $I$ inch by $1 \frac{3}{8}$ inches. He went on tolerably well for ten days, the only unfavourable feature being a dry and a loaded tongue ; after that time he began to get weak, became restless and confused, the pulse became feeble, and he died on the evening of the 18th. After death, the general aspect of the intestines was healthy ; one kidney was much enlarged and diseased, and the ureter equal in diameter to a thumb; the other kidney was absorbed, its pelvis, like a bladder, only remaining. The left side of the pelvis contained a large quantity of thick pus. The prostate was much enlarged. The bladder was thick and rugous.

CASE XCIII. - James Abercrombie, aged 70, farmer, came under treatment on December I 4 th, 1850 , and was operated on January 3 rd, 185I. The stone weighed 5 ounces, and measured $2 \frac{1}{2}$ inches by $1 \frac{1}{2}$ inches by $2 \frac{1}{8}$ inches. The third lobe of the prostate came away before the stone; it weighed 9 drachms. Bilateral section of the prostate was required to let the stone out. Purulent phlebitis in the posterior tibial vein and in the deep veins of the left leg came on, and he died on January 13th. Pus was also found in the external iliac vein. He was operated on under the influence of chloroform; his wrists and ankles were secured by broad tapes during the operation; he struggled so violently in the course of the operation that phlebitis resulted in the saphena minor vein, running up as far as the common iliac, and was the cause of death.

CASE XCIV. - James Thom, aged $7 \mathbf{I}$, farmer, was admitted on January 5 th, 1851 , and was operated on the $25^{\text {th }}$ of the same month. The stone weighed 3 drachms, and measured $1 \frac{1}{4}$ inches by $\frac{3}{4}$ inch by I inch. The urethra was torn previously to the operation by the assistant, in an unsuccessful attempt to introduce the staff, followed by such hæmorrhage as to lead to the belief that the artery of the bulb had been torn. Great infiltration of blood took place into the penis and scrotum, and sphacelus of the latter speedily followed, under which he sank. Dissection showed the laceration in the bulb nearly an inch in front of the urethral incision for lithotomy.

[To be continued.]

\section{CUTANEOUS NEUROSIS.}

By STANLEY HAYNES, M.D., Malvern Link, Worcestershire.

S. M., a strong, active, healthy, and intelligent girl of four years, complained on Tuesday, May 2nd, about midday, of feeling ill, but seemed so well that her mother, a kind and anxious parent, thought she was pretending. The child was unusually quiet, lay down all the remainder of the day, and was without appetite. No shivering was noticed. The following morning, instead of waking and getting up at six as usual, she slept soundly and uninterruptedly until twelve, when she appeared poorly, and was as on the previous day. In the evening, the child was lame and in pain; and her left great toe was found cold,

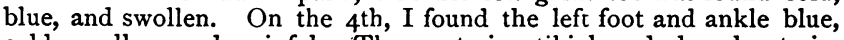
cold, swollen, and painful. The posterior tibial and dorsal arteries pulsated naturally, and no obstruction to the venous circulation was noticeable. The left hand was somewhat swollen, and there was some lividity about the finger-nails. This hand and the lower half of the forearm, and the right foot and ankle, had been in similar conditions to those in which the left foot was at the time of my visit; and all three had been very painful. The eyelids on both sides were rather and equally odematous; and the face was swollen; the lids had been affected in the same manner as the other parts. Neither the right hand or arm nor the ears had been involved. The feet had been bathed in hot water with mustard. I directed the limbs to be wrapped in cotton wadding, and prescribed a mixture with aromatic spirit of ammonia and spirit of chloroform. The child had seen a funeral on the 2 nd, but did not appear to have been frightened in any way. She was as intelligent as usual; seemed quite free from vertigo and nausea and any evidences of ergotism; her expression was rather anxious; she had taken little food; and the bowels had acted in the morning. The state of the urine had not been observed. The cardiac sounds were normal; the pulse 82. At bedtime, after some slight reaction-local pain and redness, but no sweating - the various parts had resumed their natural appearances.

The child continued well until the following morning (May 5th) at eight, when both feet became affected as before, continuing so until late at night. The patient was very poorly all day; had anorexia andthirst; her face (only) perspired copiously; and her pulse in the evening was I40. The urine was non-albuminous, loaded with magnesian phosphates.

In May I870, a playmate thrust a piece of velvet into the child's left nostril. Her mother attempted to remove it, but pushed it beyond reach and sight. Soon afterwards, some fotid discharge came away; and, at various times during the summer, threads were expelled; none were noticed for some months ; but the ozæna continued, and became so bad that the child could not be received at school. A month ago, I chloroformed the patient (as she was much frightened by any attempt to examine her nose), and endeavoured-in vain-to find and wash out any remains of the velvet. The discharge (for which a solution of carbolic acid had been used for three months) continued as before until this illness. On May $5^{\text {th }}$, there was not any discharge or bad odour. On the 6 th, the child seemed pretty well; there was not any unnatural appearance, and the ozæna returned in the afternoon. The 7 th passed without anything abnormal, and it was hoped the child had recovered; but on the 8th the left foot again became affected as before, the condition extending into the calf, and ending gradually. The ozæna continued. Both feet were very much attacked on the 9th. The little patient was as ill as on the 5th, with profuse sweating of the forehead; and the ozæna was arrested. An ounce of the following mixture was now given four times daily.

R Potassæ chloratis, gr. xxv ; tinct. ferri perchlor., spir. chloroform., ana $17 \mathrm{lxxx}$; syrupi simpl. $3 \mathrm{ij}$; aquæ dest. ad 3 viij. The feet were kept in cotton-wadding, and in the evening were restored to their natural condition. On the following day (roth), the only ab. normal state was coldness and some lividity of the posterior aspect of the lower half of the right arm; this lasted two or three hours during the middle of the day. Between ten and eleven in the morning of the IIth, both feet became much affected and very painful, with sharply defined straight lines of demarcation, until about 3 P.M., when they resumed 
their natural appearance in about an hour. The patient appeared well until the succeeding evening (12th), when the left hand was attacked up to the carpo-metacarpal articulations, corresponding with which was a distinct boundary line. On the 13 th, the right hand was slightly affected in the morning. In the middle of the day, the wrist also was very much involved, and was bounded from the arm by a distinct line. The parts were almost quite restored in the evening. The ozæna was profuse. When the child was undressed on the 14th, her parents observed a dark yellow coloration, extending the entire length of the spine, about an inch in breadth. During that day, the only other symptom noticed was, that the left elbow was decidedly colder than the right. On the $15^{\text {th }}$ and $I 7$ th, the child was quite free from all abnor. malities excepting the ozæna.

These attacks came on suddenly, the various parts affected having been seen to change from their natural condition to blue-black lividity, œdema, coldness, and hyperæsthesia, in the course of a few minutesin some instances, five minutes sufficing for the alteration. The recoveries were less rapid, but sometimes occupied some minutes only ; at others, about an hour. They occurred at various periods of the day, and appeared to be irrespective of reception of food and various ex. ternal conditions - of warmth or cold, wet or dry days, or of mental emotions. Throughout, the child had similar food to the other children of the family, and was the only one affected, and had never before ailed in a similar manner. Her father is a healthy, strong agricultural labourer; her mother is a robust and vigorous, but faint-hearted woman. Between the attacks, the patient ran about and played as usual. Sometimes while playing, at others while in bed or sitting still, she complained of pain; and then some part was found to be becomin affected. While the neurosis remained, the child was in pain, wanted to lie undisturbed, and had anorexia. The attacks sometimes lasted all day, and sometimes passed off quickly; they ceased more rapidly during the last days than when the neurosis began.

It will be observed that the left side was most affected; that the discharge from the nostril of the same side (to which it is limited) was suppressed when the symptoms first appeared; and that, when the ozæna returned on the 6th, the pseudo-gangrenous appearances ceased, but only for a time: they recurred occasionally, although the ozæna continued; so that the nasal discharge and the symptoms did not appear, as at first, to exist in any relation to each other.

There has not yet been any perceptible desquamation; nor is any expected, as the skin of the various parts has throughout been soft and pliable. During the recurrences of the neurosis, the weather has been, for May, unusually cold

In Dr. C. Handfield Jones's work on Functional Nervous Disorders (at p. 472 et seq,) are some remarks on, and cases of, somewhat analogous attacks to that now adduced.

Since the above was written the ozæna had ceased. One day in June the child expelled a foetid mass (which probably contained the remains of the velvet), and its nose has been quite free since then.

\section{SANTONIN AS A PARASITICIDE.}

By DAVİD PAGE, M.B.Edin., Kirkby Lonsdale, Westmorland.

SOME time ago, the efficacy of santonin in destroying intestinal parasites, and the peculiarity of its effects on the system, now and again observed, received a passing notice in the pages of the JOURNAL. I wish on this occasion to add a remark or two in the same direction, furnished by cases lately under my observation.

In the first of these, a healthy-looking girl, aged 12, was brought to me, suffering from loss of appetite, toothache, white-furred tongue, and symptoms generally indicating an irritable state of the prime vice. Her mother told me that, for some weeks, the navel had been the seat of great pain and uneasiness, and there were now much redness and tenderness to touch. The failure of domestic medicine had alarmed the frugal housewife, and induced her to seek a remedy elsewhere. I suspected, from the above symptoms, that the ascaris lumbricoides was lurking within the small intestines, and so gave her five-grain doses of santonin, to $b_{c}$ taken at bedtime, followed next morning by eight grains of the compound scammony powder, to be taken early before breakfast. This treatment was to be repeated for three successive nights ; but, on the morning after the second dose, I was informed that two round worms had come away by stool. One of them, which had been kept for my inspection, I found to measure fourteen inches in length. A week later, I repeated the medicine, but without any result, and the girl had already recovered her former good spirits and appetite. In spite of the large quantity of santonin administered, there was no disturbance of the eyesight or other function.
In the second case, I was consulted a fortnight ago by a country gentleman, about his youngest son, a bright little boy, aged 5 , but whose health began to cause the parents much anxiety. I found him showing all the signs of a general derangement of the gastro-intestinal tract, characterised by a very capricious and fastidious appetite, and a pale tongue, with enlarged papilla, and a slimy yellow coat along the dorsum. His bowels, too, were sluggish, and his sleep was often disturbed by waking and cries. Though, certainly, here the primary con. dition was a catarrhal state of the primæ viæ, I considered that, if the irritable symptoms depended upon parasites finding a comfortable and luxurious habitat in the excessive mucus adherent to the intestinal walls, the most prudent step would be their removal before proceeding to a tonic treatment proper to the catarrh. Santonin was therefore given as in the foregoing instance, and syrup of senna substituted for scammony, as less likely to irritate the bowels. Perhaps the old-fashioned compound decoction of aloes might have been preferable to either, seeing that the aloetic drug exerts a special stimulant and bracing action upon the small intestine, helping it to shake off the viscid mucus and allowing free osmosis to the fluids of the choked-up glands. At any rate, the immediate effect of the treatment was to dislodge a whole colony of the oxyuris or threadworm with masses of jelly-like mucus. After the first dose, much alarm was excited when it was discovered that my little patient had involuntarily passed during sleep a large quantity of urine, which stained the bed-linen bright yellow. This, I had to explain, was one of the occasional effects of santonin. The eyesight, however, was not affected. I see in Ringer's Handbook of Therapentics, that santonin is recommended as a remedy for the nocturnal incontinence of urine in children.

\section{CLINICAL MEMORANDA.}

\section{INTERMITTENT HAMATURIA OF MORE THAN TWENTY} YEARS' DURATION IN AN AGED WOMAN.

MRS. B. of Plymouth, aged 75, of a nervous and rather sanguine temperament, ceased to menstruate at 49 ; and from that time to the present, a period of twenty-six years, has been subject to attacks of intermittent hæmaturia, coming on at irregular intervals, without pain, and continuing for some months at a time, in spite of continued rest in the horizontal position; the constant use of iron, lead, gallic acid, and iced lemonade, being frequently administered as a drink when thirsty. The pulse is natural, the tongue clean, the countenance rather anæmic. She complains of debility. The urine is normal in quantity, but deeply coloured with blood, which becomes deposited in a thick grumous layer at the bottom of the utensil on the urine becoming cold. No more albumen is obtainable than may be accounted for by the presence of the blood in the urine, which is of specific gravity IOI 5 . No premonitory symptoms have characterised these attacks, such as pain, or a sense of weight at the loins, etc. The appearance of the blood has been more venous than arterial. The question naturally arises, What is the peculiar pathological condition in this extraordinary case? Has it been simply arising from periodic passive congestion of the kidneys, or has it been parasitical? Calculi, I think, may be excluded, from the total absence of pain. If not parasitical, I am inclined to regard it as a salutary effort of nature to prevent venous congestion of the system arising from the suppression of an accustomed discharge of blood.

Princess Square, Plymouth, July 3Ist, I87I.

\section{EFFECTS OF THE VAPOUR OE AMMONIA IN THE} TREATMENT OF WHOOPING-COUGH.

IN consequence of the benefits which patients have received by the inhalation of the atmosphere containing sulphuret of ammonia in the purifying-room of the gas-houses in whooping-cough, when the disease is in its last stage (that is, after the third week), I conceived the idea that ammonia might be more potently administered in the form of moist vapour by means of my "brick bath", an account of which I published in the BRITISH MEDICAL JOURNAL for August 20th, I864. Accordingly, in cases which I have had recently, I had one ounce of the strongest liquid ammonia put into a gallon of boiling water in an open pan, and the steam kept up by means of half a brick made redhot throughout and put into the boiling water containing the ammonia, and placed the pan in the centre of a room, into which I had the patients brought as the ammoniated steam was passing off. This method was used in the evening, just before bedtime; and it has been $o$ efficacious in abating the spasmodic attack, and after three or four 